\title{
Association between Health Literacy, Self-care Behavior, and Blood Sugar Level among Older Patients with Type 2 Diabetes in Rural Thai Communities
}

\author{
Wanich Suksatan ${ }^{1}$, Kantapong Prabsangob ${ }^{2}$, Bovornpot Choompunuch ${ }^{3}$ \\ ${ }^{1}$ Faculty of Nursing, HRH Princess Chulabhorn College of Medical Science, Chulabhorn Royal Academy, Bangkok, Thailand \\ ${ }^{2}$ College of Allied Health Sciences, Suan Sunandha Rajabhat University, Samut Songkram, Thailand \\ ${ }^{3}$ Faculty of Education, Mahasarakham University, Mahasarakham, Thailand
}

\section{Corresponding Author:}

Kantapong Prabsangob, $\mathrm{PhD}$

College of Allied Health Sciences, Suan

Sunandha Rajabhat University, Mueang

Samut Songkram District, Samut

Songkram 75000, Thailand

E-mail: kantapong.pr@ssru.ac.th

ORCID:

https://orcid.org/0000-0002-4409-6417

Received: October 15, 2021

Revised: December 8, 2021

Accepted: December 15, 2021
Background: Diabetes mellitus is a major problem worldwide. Moreover, older patients with significantly limited health literacy $(\mathrm{HL})$ tend to have worse self-care behaviors and health outcomes. This study aimed to describe the associations of $\mathrm{HL}$, self-care behavior, and blood sugar levels among older patients with type 2 diabetes in rural Thai communities. Methods: This cross-sectional study included 415 patients with diabetes who were purposively selected from rural Thai communities. Data were collected using questionnaires and analyzed using descriptive statistics, Pearson correlation, Spearman rho, and stepwise multiple linear regression. Results: The results revealed that most participants were women (66.50\%). The respondents had moderate overall $\mathrm{HL}(2.68 \pm 0.64)$. On average, the respondents had fair overall self-care behavior (4.0 \pm 0.33$)$. We discovered that $\mathrm{HL}$ was significantly positively correlated with self-care behavior $(r=0.90)$ but not with blood sugar level. In addition, self-care behavior was significantly negatively correlated with blood sugar level $(r=-0.50)$. Self-care behaviors and blood sugar levels were significant predictors of $\mathrm{HL}$ in patients with type 2 diabetes (total variance, 28.4\%). Conclusion: The results suggested increased HL in patients with diabetes would improve self-care behavior and, consequently, decrease their blood sugar level. Our findings indicate the need to involve nurses and multidisciplinary healthcare teams when developing health promotion programs to encourage blood sugar control.

Key Words: Health literacy, Type 2 diabetes mellitus, Blood glucose, Health behavior, Nurses

\section{INTRODUCTION}

Diabetes mellitus is a chronic condition that affects millions of people globally. According to the International Federation of Diabetes, approximately 415 million individuals worldwide had diabetes in 2015, a number that is expected to reach 642 million by $2040{ }^{1)}$ In Thailand, the prevalence of diabetes increased from $7.7 \%$ in 2004 to $7.8 \%$ in 2009 and $9.9 \%$ in $2014,{ }^{2)}$ making it the second-ranking non-communicable disease, following high blood sugar levels. ${ }^{3,4)}$ Patients with long-term diabetes and inadequate blood glucose management are prone to develop complications that result in mortality and increased disease severity, ${ }^{5,6)}$ as well as acute respiratory distress syndrome in coronavirus disease 2019 (COVID-19), ${ }^{7}$ mainly due to a higher incidence of diabetes-specific complications (e.g., coronary heart disease, stroke, kidney failure, and peripheral vascular disease).$^{8)}$ Diabetic treatment aims to maintain blood sugar levels as close to standard as feasible. Thus, after 8-12 hours of fasting, blood glucose readings must be 90 $130 \mathrm{mg} / \mathrm{dL}$ or the glycated hemoglobin (HbAlc) level $<7 \%{ }^{9}{ }^{\text {) }}$

Effective communication between patients and healthcare providers is necessary to ensure that patients correctly comprehend and follow healthcare providers' advice. The language used in communication and one's perspective on the subject under discussion are critical components of reciprocal and improved under- 
standing. Patients with a low degree of health literacy (HL) will not follow doctors' directives since they are unable to comprehend health information. Low HL is a barrier to good health, as it leads to patients' disregard for healthcare providers' advice or instructions. Additionally, a previous study reported a link between HL and self-care behavior in patients with type 2 diabetes. ${ }^{10)}$

HL or health skills were first recognized in the United States, where individuals with diverse ethnic backgrounds, languages, and cultures coexist. These individuals frequently lack an understanding of health issues and information as well as methods for better self-care management. ${ }^{11)}$ People with low HL were more likely to be careless with their health; they had high blood sugar levels, more diabetes problems, and were frequently admitted to the hospital. ${ }^{12)}$ People with diabetes who lacked functional HL were also more likely to have difficulty controlling their blood glucose levels. ${ }^{13)}$ This may result from an inability to comprehend health information recommended by healthcare specialists. Patients with a high HL may better understand the recommendations of healthcare practitioner and maintain more stable blood sugar levels.

Self-care behavior is a principal concept in health promotion that refers to decision-making and health behaviors that an individual could make to address a health issue or maintain their current level of health. ${ }^{14)}$ Self-care encompasses four dimensions: the physical, averting complications, treatment, and psychosocial dimensions. ${ }^{15)}$ Additionally, patients must learn to motivate themselves and gain social support to sustain their efforts. ${ }^{16)}$ On the other hand, social support, particularly from peers, friends, and families, is also a barrier to treatment adherence and self-care, although high levels of support are connected with greater long-term self-care management. As such, this study aimed to improve the understanding of the relationships between HL and self-care behaviors and blood sugar levels in patients with type 2 diabetes living in rural Thai communities.

\section{MATERIALS AND METHODS}

\section{Research Design and Sampling}

The sample in this cross-sectional survey consisted of 60- to 80 -year-old male and female adults living in Samut Songkram Province in southern central Thailand, which comprises three districts: Samut, Amphawa, and Bangkhonthi. This province is an important economic area in the central part of Thailand, where most residents produce palm sugar as a household industry. Bangkhonthi District has 13 sub-district health promotion hospitals, three of which-Jormploug, Bang Prom, and Bang Yeerong — are primary care centers. Each center serves three to five sub-district health promotion hospitals. In this study, we selected a sample of 415 pa- tients with diabetes living in rural Thai communities.

\section{Research Instruments}

The survey questionnaires used in the current study were divided into the following four research instruments.

\section{Self-care behavior assessment (SBA)}

The SBA is based on the concept of self-care behavior theory first described by Orem. ${ }^{15)}$ We applied a questionnaire developed by Suksatan and Prabsangob. ${ }^{10)}$ The self-care behavior questionnaire included four dimensions (physical, prevention of complications, treatment, and psychosocial), each of which comprised five questions. The participants answered each question by rating their response from 1 (never) to 5 (always). The total score for self-care behaviors was 100 points, with higher scores indicating better selfcare behavior.

\section{Blood sugar control assessment (BSCA)}

We used Dextrostix (DTX), which is the preferred method for diabetes screening and diagnosis. DTX was used to assess blood glucose levels after fasting for at least 6-8 hours. We used the latest DTX results from patients' health records at the health promotion hospitals, which were assessed by technicians the sub-district health promotion hospitals.

\section{Health literacy scale (HLS)}

We applied the three-level HLS developed by Ishikawa et al., ${ }^{17)}$ to assess the HL level. The test is used to measure functional, communicative, and critical HL and consists of three groups of questions based on three different levels of HL: basic (composed five questions), interactive (five questions), and critical (four questions). The participants were asked to read the questions or to have them read to them. The patients answered each question by rating their responses from 1 (never) to 4 (regular). Then, the scores of each group of questions were collected and divided by the number of questions. The score results ranged between 1 and 4, with higher scores indicating higher HL, except for the score result of basic $\mathrm{HL}$, in which a higher score indicated a lower HL. We used the total HL score in this study ( 56 points: 14 multiplied by 4) by defining percentage scores of <60\%,60\%-69.99\%, 70\%-79.99\%, and $>79.99 \%$, indicating poor, fair, good, and very good HL, respectively.

\section{Sociodemographic variables}

We assessed the general information of the participants using an instrument with five items: sex, age, education level, monthly income, and diabetes duration. 


\section{Data Analysis}

We used IBM SPSS Statistics for Windows version 21.0 (IBM, Armonk, NY, USA) to analyze the data. The frequencies, percentages, means, and standard deviations of the data were presented. Pearson correlation coefficient and Spearman rho were used to examine the relationships between the participants' sociodemographic factors, self-care behaviors, and blood sugar levels and their HL. We used a stepwise multiple linear regression analysis to test the factors predicting these variables. The significance level was set at $\mathrm{p}<0.05$.

\section{Ethical Considerations}

The current study was carried out according to the ethical principles of the Declaration of Helsinki. Written informed consent was obtained from all the participants. Ethical approval was attained from the Suan Sunandha Rajabhat University Institutional Review Board on human rights prior to commencing the study (No. COA.1037/2018).

\section{RESULTS}

We purposively selected a total of 415 participants receiving health services at sub-district health promotion hospitals in rural Thai communities as a sample group. The demographic data and clinical characteristics of the participants were as follows: $66.50 \%$ female $(n=276)$ and a mean age of 64.1 years. Most participants had graduated from primary school $(71.30 \%, \mathrm{n}=29)$ and $65 \%$ of participants had a monthly income of $<5,001$ Thai Baht $(n=164)$. Furthermore, most participants had had diabetes for 5-9 years $(39.80 \%, \mathrm{n}=165)$ and most had blood sugar levels of $126-154 \mathrm{~mL} / \mathrm{dL}$ (51.45\%, $\mathrm{n}=214$ ) (Table 1).

\section{Participant HL}

The participants had fair overall HL (mean, 2.68), with a mean total score of 36.89. The mean scores for functional, interactive, and critical HL were 3.11, 2.32, and 2.61, respectively (Table 2).

\section{Participant Self-care Behaviors}

The participants had a mean score of overall self-care behavior of 4.00. The mean score was highest for the treatment dimension (4.34), followed by the physical (4.00), prevention of complications (3.89), and psychosocial (3.75) dimensions (Table 3).

\section{Relationships of Participants' Sociodemographic Characteristics, HL, Self-care Behaviors, and Blood Sugar Levels}

Pearson correlation coefficient analysis showed that HL was significantly positively correlated with self-care behavior $(r=0.90$,
Table 1. Demographic characteristics of the participants

\begin{tabular}{|c|c|}
\hline Characteristic & Value \\
\hline \multicolumn{2}{|l|}{ Sex } \\
\hline Male & $139(33.50)$ \\
\hline Female & $276(66.50)$ \\
\hline Age (y) & $64.1 \pm 8.1(50-80)$ \\
\hline $50-59$ & $148(35.70)$ \\
\hline $60-69$ & $175(42.20)$ \\
\hline $70-80$ & $92(22.10)$ \\
\hline \multicolumn{2}{|l|}{ Education levels } \\
\hline Lower than primary school & $36(8.70)$ \\
\hline Primary school & $296(71.30)$ \\
\hline Secondary/Vocational school & $64(15.40)$ \\
\hline Bachelor's degree and above & $19(4.60)$ \\
\hline \multicolumn{2}{|l|}{ Monthly income (Thai Baht) } \\
\hline$<5,001$ & $164(39.51)$ \\
\hline $5,001-10,000$ & $139(33.49)$ \\
\hline $10,001-15,000$ & $80(19.30)$ \\
\hline $15,001-20,000$ & $16(3.85)$ \\
\hline$>20,000$ & $16(3.85)$ \\
\hline \multicolumn{2}{|l|}{ Duration of diabetes $(y)$} \\
\hline$<5$ & $105(25.20)$ \\
\hline $5-9$ & $165(39.80)$ \\
\hline$>10$ & $145(35.00)$ \\
\hline \multicolumn{2}{|l|}{ Blood sugar, DTX (mL/dL) } \\
\hline$<126$ & $125(30.10)$ \\
\hline $126-154$ & $214(51.45)$ \\
\hline $155-182$ & $60(14.56)$ \\
\hline$>182$ & $16(3.89)$ \\
\hline
\end{tabular}

Values are presented as number (\%) or mean \pm standard deviation (min-max). DTX, Dextrostix.

Table 2. Health literacy of the participants

\begin{tabular}{lrc}
\hline Health literacy & Mean \pm SD & Interpretation \\
\hline Functional & $3.11 \pm 0.86$ & High \\
Interactive & $2.32 \pm 0.86$ & Fair \\
Critical & $2.61 \pm 0.96$ & Fair \\
Total (range 1-4) & $2.68 \pm 0.64$ & Fair \\
Total score (range 14-56) & $36.89 \pm 7.11$ & Fair \\
\hline
\end{tabular}

$\mathrm{SD}$, standard deviation.

Table 3. Self-care behavior of the participants

\begin{tabular}{ll}
\hline Self-care behavior & Mean \pm SD \\
\hline Physical dimension & $4.00 \pm 0.71$ \\
Prevented complication dimension & $3.89 \pm 0.53$ \\
Treatment dimension & $4.36 \pm 0.40$ \\
Psychosocial dimension & $3.75 \pm 0.72$ \\
Total self-care behavior & $4.00 \pm 0.33$
\end{tabular}

SD, standard deviation 
$\mathrm{p}<0.001)$ but not blood sugar levels $(\mathrm{r}=-0.023, \mathrm{p}=0.638)$. In addition, self-care behavior was significantly negatively correlated with blood sugar levels $(\mathrm{r}=-0.50, \mathrm{p}<0.001)$. Positive correlations were observed between patient education and self-care behaviors $(\mathrm{r}=0.36, \mathrm{p}<0.05)$ and HL $(\mathrm{r}=0.38, \mathrm{p}<0.05)$. We also observed significant positive correlation between patient age and blood sugar levels $(\mathrm{r}=0.28, \mathrm{p}<0.05)$, self-care behavior $(\mathrm{r}=0.22, \mathrm{p}<0.05)$, and HL $(\mathrm{r}=0.30, \mathrm{p}<0.05)$ (Table 4$)$.

\section{Factors Predicting HL}

Stepwise multiple regression analysis to identify factors that could predict HL identified self-care behaviors and blood sugar levels (beta $=0.419$ and 0.230 , respectively). Combined, these factors predicted HL with $28.4 \%$ accuracy (Table 5).

\section{DISCUSSION}

The low HL levels among older adults with type 2 diabetes in rural Thai communities could be explained by their advanced age, lack of education, and low income. Our findings are consistent with those of Schillinger et al. ${ }^{18)}$ and Manganello ${ }^{19)}$ who established the prevalence of inadequate $\mathrm{HL}$ among low-income and undereducated older adult patients with diabetes. Our examination of each facet of HL revealed the lowest mean score for interactive HL compared to functional and critical HL. Interactive HL refers to being literate in basic health and cognitive and social skills used to participate in social activities and select updated information to improve health behaviors. ${ }^{20,21)}$ Low interactive $\mathrm{HL}$ indicates that patients with diabetes have less communication with others regarding their health and diabetes. ${ }^{10)}$

Our results also revealed interesting relationships between patient age, blood sugar levels, self-care behaviors, and HL. Patient age was associated with HL in Spearman rho tests, although the association disappeared when communicative HL was included in the model. Previous studies have also reported an association be- tween patient age and blood sugar levels, ${ }^{2,21)}$ self-care behaviors, ${ }^{21,22)}$ and $\mathrm{HL} .{ }^{2,21,23)}$ Contrary to previous findings, patient age was not associated with $\mathrm{HL}$ in older adults in urban communities in Thailand. ${ }^{1424)}$

The current study's findings indicated that HL was associated with positive self-care behaviors, whereas self-care behaviors were negatively associated with blood sugar levels. Thus, increasing HL in patients with diabetes results in improved self-care behavior and, as a result, lower blood sugar levels. ${ }^{23)}$ This finding is consistent with those of a previous study reporting a relationship between low HL and failure to control blood glucose levels in patients with type 2 diabetes. ${ }^{18)}$ This occurred because diabetic patients with low $\mathrm{HL}$ frequently had difficulty reading medicine labels or comprehending blood sugar levels results and healthcare provider's prescriptions. ${ }^{22)}$ Thus, patients were unable to practice effective self-care. Additionally, patients with low HL frequently did not know or recall the names of medications or how to use them ${ }^{25)}$ and were unaware of their health condition and how to manage it. ${ }^{26)}$ Patients with low HL demonstrated difficulties in remembering and comprehending medical information. This prevented them from gathering or searching for additional information, as they could not comprehend or recall the details received from hospitals due to ineffective communication. ${ }^{25)}$ Furthermore, in their comparisons of communication levels between healthcare providers and patients with adequate and low HL. Schillinger et al. ${ }^{18)}$ reported that healthcare providers rarely explained health conditions and treatment steps to the low HL group in a way that the patients

Table 5. Results of the stepwise multiple regression analysis between predictors and health literacy among the study participants

\begin{tabular}{lccccr}
\hline Predicting factors & B & SE & Beta & t & p-value \\
\hline Constant & 2.340 & 0.561 & & -4.172 & $<0.001$ \\
Self-care behaviors & 0.240 & 0.060 & 0.419 & 4.029 & $<0.001$ \\
Blood sugar levels & 0.126 & 0.054 & 0.230 & 2.336 & 0.002
\end{tabular}

$\mathrm{R}^{2}=0.299$, adjusted $\mathrm{R}^{2}=0.284$.

Table 4. Correlations between participant sociodemographic characteristics, health literacy, self-care behavior, and blood sugar level

\begin{tabular}{|c|c|c|c|c|c|c|c|c|}
\hline Variable & Mean \pm SD & Age & Education & Monthly income & Duration of diabetes & Blood sugar levels & Self-care behavior & Health literacy \\
\hline Age & $64.11 \pm 8.10$ & & & & & & & \\
\hline Education & $3.04 \pm 0.62$ & $0.34^{\mathrm{a})}$ & & & & & & \\
\hline Monthly income & $6,232.5 \pm 984.3$ & $-0.52^{\mathrm{b})}$ & $0.93^{\mathrm{a})}$ & & & & & \\
\hline Duration of diabetes & $6.42 \pm 2.53$ & $0.37^{\mathrm{b})}$ & $0.06^{\mathrm{a})}$ & $0.20^{\mathrm{b})}$ & & & & \\
\hline Blood sugar levels & $134.60 \pm 32.47$ & $0.28^{\mathrm{b})^{*}}$ & $0.62^{\mathrm{a})}$ & $0.28^{\mathrm{b})}$ & $0.46^{\mathrm{b})}$ & & & \\
\hline Self-care behavior & $4.00 \pm 0.33$ & $0.22^{\mathrm{b})^{*}}$ & $0.36^{\mathrm{a})^{*}}$ & $0.08^{\mathrm{a})}$ & $0.38^{\mathrm{b})}$ & $-0.50^{\mathrm{b})^{* *}}$ & & \\
\hline Health literacy & $147.46 \pm 41.91$ & $0.30^{\mathrm{b})^{*}}$ & $0.38^{\mathrm{a})^{*}}$ & $0.09^{\mathrm{b})^{*}}$ & $0.44^{\mathrm{b})}$ & $-0.23^{\mathrm{b})}$ & $0.90^{\mathrm{b})^{*}}$ & \\
\hline
\end{tabular}

SD, standard deviation.

${ }^{\text {a) }}$ Spearman rho, ${ }^{\text {b) }}$ Pearson correlation.

${ }^{*} \mathrm{p}<0.05$ (two-tailed), ${ }^{* *} \mathrm{p}<0.01$ (two-tailed). 
could understand and apply. That study also reported that HL was not significantly associated with blood sugar levels.

Despite receiving education from health providers about diabetes, patient blood sugar control did not improve because the patients did not apply the knowledge. Healthcare service providers must have knowledge and understanding of patients' thoughts and points of view regarding meeting with healthcare providers. While many patients understand and remember the health information and behavior changes provided by healthcare providers, many do not practice these recommendations; rather, the patients' attitudes or views about diabetes are contrary to those of the healthcare providers.

Finally, we found that self-care behaviors and blood sugar levels were predictors of $\mathrm{HL}$ in Thai patients with type 2 diabetes. The results of the current study are consistent with those of Yodmai et al. $^{14)}$ and Caruso et al. ${ }^{23)}$ demonstrating the importance of self-care behaviors and maintaining blood glucose levels to improving the physical and mental health behaviors of patients with type 2 diabetes, which are associated with HL.

The present study has some limitations. First, the participants were patients with type 2 diabetes who received care in only one province in Thailand. This may limit the generalizability of our findings to other patients with type 2 diabetes in different contexts (e.g., urban communities, nursing homes). Second, the sample was obtained using a purposive selection method. The lack of random sampling may have resulted in sample selection bias, limiting the generalizability of the findings. Third, we used only the DTX method to assess blood glucose levels after fasting for at least 6-8 hours. However, this method shows potential for mass screening programs for patients with type 2 diabetes, as it accurately classified patients and provided rapid results. Future studies should use other methods to evaluate blood glucose levels that are standard and accurate for patients with type 2 diabetes, such as fasting plasma glucose or $\mathrm{HbAl}$ c levels. Fourth, we examined the relationship between HL, self-care behaviors, and blood sugar levels among older patients with type 2 diabetes using only a self-reported questionnaire. Future interventional or longitudinal studies are needed to clarify the long-term outcomes of patients with diabetes. Fifth, we did not examine the severity of type 2 diabetes. Therefore, additional studies are needed to examine the relationship between $\mathrm{HL}$ and disease severity in type 2 diabetes, such as emergency room visits, treatment intensity, and time off work due to diabetes. Finally, we assessed HL, self-care behavior, and blood sugar levels among older patients with type 2 diabetes. Our findings would be more informative if social support, family support, access to healthcare information, and perceived self-efficacy were included, which might have also significantly affected patient HL.
In conclusion, the results of the current study demonstrated moderate $\mathrm{HL}$ in most older adult patients with type 2 diabetes in Thai communities. Increased HL among these patients was associated with better self-care behavior and, consequently, decreased blood sugar levels. Nurses and healthcare providers should be involved when developing health promotion programs to encourage blood sugar control and improve patient quality of life, particularly in older adults with diabetes.

\section{ACKNOWLEDGMENTS}

\section{CONFLICT OF INTEREST}

The researchers claim no conflicts of interest.

\section{FUNDING}

None.

\section{AUTHOR CONTRIBUTION}

Conceptualization, WS, KP, BP; Data curation, WS, KP; Funding acquisition, WS, KP, BC; Investigation, WS, KP; Methodology, WS, BC; Project administration, WS, KP; Supervision, WS; Writing-original draft, WS, KP; Writing-review \& editing, WS, KP, BP.

\section{REFERENCES}

1. Nanditha A, Ma RC, Ramachandran A, Snehalatha C, Chan JC, Chia KS, et al. Diabetes in Asia and the Pacific: implications for the global epidemic. Diabetes Care 2016;39:472-85.

2. Aekplakorn W, Chariyalertsak S, Kessomboon P, Assanangkornchai S, Taneepanichskul S, Putwatana P. Prevalence of diabetes and relationship with socioeconomic status in the Thai population: National Health Examination Survey, 2004-2014. J Diabetes Res 2018;2018:1654530.

3. Posai V, Suksatan W, Choompunuch B, Koontalay A, Ounprasertsuk J, Sadang JM. Assessment of the health-promoting behaviors of hospitalized patients with non-communicable diseases during the second wave of COVID-19. J Multidiscip Healthc 2021;14:2185-94.

4. Moon S, Roh YK, Yoon JL, Jang KU, Jung HJ, Yoo HJ, et al. Clinical features of geriatric syndromes in older Koreans with diabetes mellitus. Ann Geriatr Med Res 2019;23:176-82.

5. Suksatan W. Health-promoting behaviors and related factors in patients with chronic diseases in a rural community. Syst Rev Pharm 2020;11:624-7.

6. Lekamwasam R, Lekamwasam S. Effects of COVID-19 pandemic on health and wellbeing of older people: a comprehensive review. Ann Geriatr Med Res 2020;24:166-72. 
7. Kumar A, Arora A, Sharma P, Anikhindi SA, Bansal N, Singla V, et al. Is diabetes mellitus associated with mortality and severity of COVID-19? A meta-analysis. Diabetes Metab Syndr 2020; 14:535-45.

8. Huang I, Lim MA, Pranata R. Diabetes mellitus is associated with increased mortality and severity of disease in COVID-19 pneumonia: a systematic review, meta-analysis, and meta-regression. Diabetes Metab Syndr 2020;14:395-403.

9. Bantle JP, Wylie-Rosett J, Albright AL, Apovian CM, Clark NG, Franz MJ, et al. Nutrition recommendations and interventions for diabetes 2006: a position statement of the American Diabetes Association. Diabetes Care 2006;29:2140-57.

10. Suksathan W, Prabsangob K. Health literacy and self-care behavior in elderly with diabetes in Ratchaburi Province, Thailand. Int J Manag Appl Sci 2016;2:21-4.

11. Abdullah A, Liew SM, Salim H, Ng CJ, Chinna K. Prevalence of limited health literacy among patients with type 2 diabetes mellitus: a systematic review. PLoS One 2019;14:e216402.

12. Baker DW, Gazmararian JA, Williams MV, Scott T, Parker RM, Green D, et al. Functional health literacy and the risk of hospital admission among Medicare managed care enrollees. Am J Public Health 2002;92:1278-83.

13. Gazmararian JA, Baker DW, Williams MV, Parker RM, Scott TL, Green DC, et al. Health literacy among Medicare enrollees in a managed care organization. JAMA 1999;281:545-51.

14. Yodmai K, Pechrapa K, Kittipichai W, Charupoonpol P, Suksatan W. Factors associated with good COVID-19 preventive behaviors among older adults in urban communities in Thailand. J Prim Care Community Health 2021;12:21501327211036251.

15. Orem DE. Nursing: concepts of practice. 4th ed. St. Louis, MO: Mosby; 1991.

16. Suksatan W, Tankumpuan T. Depression and rehospitalization in patients with heart failure after discharge from hospital to home: an integrative review. Home Health Care Manag Pract 2021 Jan 19 [Epub]. https://doi.org/10.1177\%2F1084822320986965.

17. Ishikawa H, Takeuchi T, Yano E. Measuring functional, communicative, and critical health literacy among diabetic patients. Diabetes Care 2008;31:874-9.

18. Schillinger D, Grumbach K, Piette J, Wang F, Osmond D, Daher C, et al. Association of health literacy with diabetes outcomes. JAMA 2002;288:475-82.

19. Manganello JA. Health literacy and adolescents: a framework and agenda for future research. Health Educ Res 2008;23:840-7.

20. Berkman ND, Davis TC, McCormack L. Health literacy: what is it? J Health Commun 2010;15 Suppl 2:9-19.

21. Marciano L, Camerini AL, Schulz PJ. The role of health literacy in diabetes knowledge, self-care, and glycemic control: a meta-analysis.J Gen Intern Med 2019;34:1007-17.

22. Saeed H, Saleem Z, Naeem R, Shahzadi I, Islam M. Impact of health literacy on diabetes outcomes: a cross-sectional study from Lahore, Pakistan. Public Health 2018;156:8-14.

23. Caruso R, Magon A, Baroni I, Dellafiore F, Arrigoni C, Pittella F, et al. Health literacy in type 2 diabetes patients: a systematic review of systematic reviews. Acta Diabetol 2018;55:1-12.

24. Pechrapa K, Yodmai K, Kittipichai W, Charupoonpol P, Suksatan W. Health literacy among older adults during the coronavirus disease 2019 pandemic: a cross-sectional study in an urban community in Thailand. Ann Geriatr Med Res 2021 Nov 5 [Epub]. https://doi.org/10.4235/agmr.21.0090.

25. Williams MV, Baker DW, Parker RM, Nurss JR. Relationship of functional health literacy to patients' knowledge of their chronic disease: a study of patients with hypertension and diabetes. Arch Intern Med 1998;158:166-72.

26. Kalichman SC, Rompa D. Functional health literacy is associated with health status and health-related knowledge in people living with HIV-AIDS. J Acquir Immune Defic Syndr 2000;25:337-44. 